Didáctica. Lengua y literatura

ISSN: 1130-0531

http://dx.doi.org/10.5209/DIDA.61963

\title{
El teatro del exilio en las aulas de Bachillerato: el tratamiento del tema de los refugiados a través de San Juan de Max Aub
}

\author{
Diego Santos Sánchez ${ }^{1}$
}

Recibido: 14 de septiembre de 2017 / Aceptado: 6 de junio de 2018

Resumen. Tras una pertinente reflexión teórica, este trabajo plantea una actividad de aula para segundo de Bachillerato en que se trabaja el tema de los refugiados sirios a partir de un texto teatral de Max Aub que versa sobre la diáspora judía contemporánea. La actividad plantea un tema pertinente y ahonda en el tratamiento de los derechos humanos, que son un tema central para todo el periodo de la educación secundaria. Al mismo tiempo, esta actividad parte de un texto teatral e incorpora dramatizaciones y debates, recursos que contribuyen a incrementar la motivación y a producir un aprendizaje más relevante y duradero. Por último, la elección del texto redunda en la pluralización del canon literario que se maneja en el Bachillerato.

Palabras clave: Teatro; refugiados; diáspora judía; exilio; Max Aub.

\section{[en] Exile Theatre in Secondary Education: Dealing with the Refugees Through Max Aub's San Juan}

\begin{abstract}
Following some theoretical discussion, this article proposes a classroom activity for the last course of sencondary education in which the case of Syrian refugees is dealt with through a play on contemporary Jewish diaspora by Max Aub. The proposed activity brings in a relevant topic and allows for work on human rights, central to sencondary education. At the same time, this activity departs from a play and features dramatizations and debates, which are resources that boost motivation and allow for a more relevant and long-term learning. Lastly, choosing this text pluralizes the literary canon in secondary education.
\end{abstract}

Keywords: Theatre; refugees; Jewish diaspora; exile; Max Aub.

\section{[fr] Le théâtre de l'exil dans le Baccalauréat: le sujet des réfugiés à travers San Juan de Max Aub}

Résumé. Après une réflexion théorique pertinente, ce travail présente une activité pour la deuxième année de Baccalauréat dans laquelle le sujet des réfugiés syriens est travaillé à partir d'un texte théâtral de Max Aub qui traite de la diaspora juive. L'activité offre un sujet pertinent et permet le travaille sur les droits de l'homme, qui est un thème central pour toute la période de l'enseignement secondaire. En même temps, cette activité commence par un texte théâtral et intègre des dramatisations et des débats, des ressources qui contribuent à accroître la motivation et à produire un apprentissage plus pertinent et durable. Enfin, le choix du texte résulte de la pluralisation du canon littéraire qui est traité dans le Baccalauréat.

Mots-clés: Théâtre; réfugiés; diaspora juive; exile; Max Aub.

$1 \quad$ Universidad Complutense de Madrid (España)
E-mail: diego.santos@ucm.es 
Sumario. 1. Introducción. 2. Educación en valores. 3. El teatro en el proceso de enseñanza-aprendizaje. 4. El exilio republicano de 1939 en los cánones educativos. 5. Propuesta didáctica. 5.1. Fase previa y contextualización. 5.2. Ejecución. 5.3. Cierre. 6. Conclusión. 7. Referencias bibliográficas.

Cómo citar: Santos Sánchez, D. (2018) El teatro del exilio en las aulas de Bachillerato: el tratamiento del tema de los refugiados a través de San Juan de Max Aub, Didáctica. Lengua y Literatura, 30, 201219.

\section{Introducción}

El mundo en que vivimos está marcado por conflictos que acarrean largos contingentes de desplazados. La guerra de Siria, por citar el ejemplo más sangrante, ha derivado en una crisis de refugiados sin precedentes que supone un desafío para las sociedades europeas no solo porque su capacidad material de acogida se ve puesta a prueba, sino también porque la llegada de refugiados sirve de aliciente para que algunos sectores de la sociedad agiten las banderas del odio al diferente, que en esta ocasión toma el nombre de islamofobia. Para luchar contra esta lacra, especialmente tras los atentados de Barcelona en agosto de 2017, conviene atajar este problema. Se hace, por tanto, preciso acabar con el estigma que se aplica al otro (en este caso el musulmán) al tiempo que se han de reforzar los valores críticos y poner de relieve la necesidad de preservar los derechos humanos.

Una de las formas de tratar este tema candente en nuestras sociedades es a través de la educación. En este sentido, el presente trabajo plantea una propuesta didáctica en el seno de la asignatura Lengua castellana y Literatura para reflexionar sobre un aspecto particular de los derechos humanos: la xenofobia y el fenómeno de los refugiados que buscan refugio fuera de su país. Para ello se partirá del texto teatral San Juan de Max Aub: ambientada en los tiempos de los pogroms contra los judíos, la obra toca de lleno la violencia racista y xenófoba y plantea una situación en que ningún país quiere hacerse cargo de un largo contingente de refugiados que vaga a la deriva por el mar Mediterráneo. Son varias las razones que abogan por la elección de este texto para trazar nuestra propuesta. Por un lado, el hecho de que el texto verse sobre la diáspora judía del siglo XX, un episodio más de la genealogía de exilios del mundo contemporáneo, lo hace especialmente idóneo para someterlo a una lectura contemporaneizadora que nos permita establecer un diálogo entre esa diáspora y la de los refugiados de nuestros días. La ley educativa, como veremos más adelante, plantea la necesidad de tratar de manera explícita la xenofobia y la cuestión judía. Por otro lado, la pertenencia del autor del texto al colectivo de los exiliados republicanos permitirá poner en relación este grupo humano, en buena medida desconocido, con la situación de los judíos y de los refugiados de la actualidad. Así, el hecho de que Max Aub tuviese que abandonar su país hará posible trazar vínculos entre las distintas formas de la barbarie a lo largo de la historia y fomentar así el pensamiento crítico en el alumnado. Por último, la naturaleza teatral del texto permitirá desarrollar en el aula una serie de actividades interactivas y motivadoras que ofrecen ventajas sobre el trabajo con textos de corte narrativo. 
La estructura de este trabajo es doble y responde a una consecución de planteamientos teóricos y propuestas didácticas. Primeramente se aborda la justificación de la propuesta desde el punto de vista legal, amparándola en los planteamientos que hace la LOMCE en cuanto a competencias, contenidos y objetivos tanto para el Bachillerato como para la asignatura de Lengua castellana y Literatura. A continuación de propondrá una justificación teórica de la potencialidad del teatro en el aula en su doble vertiente textual y performativa. La parte teórica se cerrará con una valoración de los beneficios que esta propuesta encierra para la pluralización del canon en la asignatura de Lengua castellana y Literatura. Por último, en el quinto epígrafe se planteará la propuesta didáctica con las indicaciones pertinentes para ser llevada al aula.

\section{Educación en valores}

Mediante el Real Decreto 1105/2014, la LOMCE establece que las competencias para el currículo de Educación Secundaria Obligatoria y Bachillerato, entendidas como la capacidad de aplicar de forma integrada los contenidos para que el alumnado resuelva de manera eficaz problemas complejos, son siete: la lingüística, la matemática y científico-tecnológica, la digital, la de aprender a aprender, las sociales y cívicas, el espíritu emprendedor y la conciencia y expresión cultural (BOE, 172). Con la propuesta que se hace en estas páginas pretendemos abordar en el aula de Lengua castellana y Literatura del segundo curso de Bachillerato la competencia social y cívica para fomentar la educación en valores a través de una reflexión crítica del tema de la xenofobia y los refugiados. Del mismo modo, conviene tener en cuenta que el marco legal plantea la necesidad de que el proceso de enseñanza-aprendizaje sea holístico e integrador; para que se produzca esa deseada "adquisición eficaz de las competencias y su integración efectiva en el currículo, deberán diseñarse actividades de aprendizaje integradas que permitan al alumnado avanzar hacia los resultados de aprendizaje de más de una competencia al mismo tiempo" (BOE, 172). En este sentido, este trabajo propone una aplicación didáctica en que la competencia social y cívica se pone en práctica junto con otras dos: la competencia lingüística, por un lado, y la conciencia cultural, por otro. Así, el trabajo conjunto de varias competencias se articulará en torno al tratamiento de un texto teatral (a un tiempo producto lingüístico y cultural), que planteará una serie de actividades a través de las que el alumnado cobrará la noción de que la literatura es reflejo de la realidad y puede ofrecerles claves con que interpretarla. En este sentido, esta propuesta intenta poner de relieve ese espíritu integrador que reclama el marco legal.

Hay que notar que la LOMCE insta a las administraciones educativas a fomentar, como un elemento transversal a lo largo de toda la etapa educativa de la ESO y el Bachillerato, el aprendizaje de

los valores que sustentan la libertad, la justicia, la igualdad, el pluralismo político, la paz, la democracia, el respeto a los derechos humanos, el respeto a los hombre y mujeres por igual, a las personas con discapacidad y el rechazo a la violencia terrorista, la pluralidad, el respeto al Estado de derecho, el respeto y consideración a las víctimas del terrorismo y la prevención del terrorismo y de cualquier tipo de violencia $(\mathrm{BOE}, 174)$ 
Y, más en consonancia con nuestra propuesta, la prevención "de la violencia contra las personas con discapacidad, de la violencia terrorista y de cualquier forma de violencia, racismo o xenofobia, incluido el estudio del Holocausto judío como hecho histórico" (BOE, 174). De especial interés parece, pues, el tratamiento del racismo y la xenofobia a través del Holocausto judío, así como de otras manifestaciones similares que, como los pogroms, han marcado de manera indeleble el destino de la comunidad judía. Estos contenidos, que a priori son cubiertos por las asignaturas de Historia, deben ser, como indica la ley, tratados de manera transversal a lo largo de esta etapa educativa. Nuestra propuesta parte precisamente de esta necesidad: si por un lado se articula en torno a un texto teatral que permite trabajar la xenofobia contra los judíos y, a través de ella, el fenómeno de los refugiados, por otro plantea su tratamiento en el aula de Lengua castellana y Literatura proponiendo un aprendizaje competencial basado en una visión transversal, dinámica e integral que se sustenta, a su vez, en un planteamiento interdisciplinar (BOE, 170-71). Esta opción es, además, especialmente relevante por la propia estructura del Bachillerato. A pesar de ser considerados centrales por la LOMCE, estos contenidos se ven, no obstante, generalmente relegados al ámbito de la Historia, como se ha apuntado más arriba. Sin embargo, no se trata de contenidos del programa de la Historia de España, obligatoria en el Bachillerato, sino más bien de la Historia del Mundo Contemporáneo, que es una optativa únicamente para los itinerarios de Artes y Humanidades y Ciencias Sociales. De ahí se deriva el hecho de que un gran número de estudiantes acabará su recorrido educativo sin haber tratado este fenómeno a lo largo de su proceso formativo. Consideramos que esto justifica la necesidad de abordar este contenido a través de una propuesta en el marco de la asignatura de Lengua castellana y Literatura.

Según la LOMCE, la finalidad de la asignatura Lengua castellana y Literatura tanto en ESO como en Bachillerato es "el desarrollo de la competencia comunicativa del alumnado, entendida en todas sus vertientes: pragmática, lingüística, sociolingüística y literaria" (BOE, 357). Al margen de esa competencia literaria, la ley señala también que la lectura de textos de distintos géneros literarios ha de servir también para que el estudiante llegue a desarrollar "su propio pensamiento crítico" (BOE, 358). Es en este desarrollo donde se ancla nuestra propuesta, que toma un texto teatral y su potencialidad dramática como detonantes para la reflexión crítica sobre el tema apuntado más arriba. Además, nuestra opción se justifica en el hecho de que la asignatura de Lengua castellana y Literatura debe pretender, en los cursos del Bachillerato, que "el alumnado profundice en la relación entre el contexto sociocultural y la obra literaria" (BOE, 359); en este sentido, uno de los criterios de evaluación que marca la ley es la capacidad de "interpretar de manera crítica fragmentos u obras de la literatura del siglo XX hasta nuestros días, reconociendo las ideas que manifiestan la relación de la obra con su contexto histórico, artístico y cultural" (BOE, 378). De este modo, la decisión de trabajar, como se plantea en estas páginas, el San Juan de Max Aub en segundo de Bachillerato está justificada no solo por el modo integrador en que se abordan competencias y objetivos, sino también desde el punto de vista del propio proceso evaluativo, ya que el / la docente podrá valorar si al final de la secuencia didáctica que se plantea en estas páginas el alumnado es capaz, según los estándares de aprendizaje evaluables, de trazar una reflexión crítica en clave de actualidad partiendo de un texto literario del siglo pasado.

La LOMCE señala entre los objetivos del Bachillerato el desarrollo en los alumnos y las alumnas de capacidades que les permitan "adquirir una conciencia cívica 
responsable, inspirada por los valores de la Constitución española así como por los derechos humanos, que fomente la corresponsabilidad en la construcción de una sociedad justa y equitativa", así como "conocer y valorar críticamente las realidades del mundo contemporáneo, sus antecedentes históricos y los principales factores de su evolución" (BOE, 188). En este sentido, nuestra propuesta propone, desde su interdisciplinariedad y su carácter integrador, trabajar de manera conjunta estos objetivos a través de la combinación de las competencias social y cívica, lingüística y cultural, como se apuntaba más arriba. En muchas ocasiones, sin embargo, estas metas educativas no son debidamente perseguidas en el aula, donde hay una tendencia a continuar el formato de clase magistral que, a su vez, legitima "la reproducción memorística de datos que responden a un enfoque tradicional de enseñanza y al modelo didáctico, en teoría desterrado de los centros educativos, de la historia de la literatura" (Vila Carneiro, 2017). Esta actitud deja de lado el desarrollo de la capacidad de formular interpretaciones personales y críticas que, desde lecturas multidimensionales, permitan poner en relación las obras literarias con la realidad del alumnado.

Esto es especialmente así en segundo de Bachillerato: por su carácter propedéutico, el curso se enfoca generalmente hacia las pruebas de acceso a la universidad y, por tanto, privilegia los contenidos sobre el desarrollo de componentes más transversales. Sin embargo, el alumnado de ese curso, al filo ya de la mayoría de edad, posee capacidades cognitivas, éticas y cívicas que abogan por la introducción de contenidos del tipo de los descritos más arriba, que redundan en su desarrollo como ciudadanos críticos, maduros y responsables. Consideramos, por tanto, que actividades de este tipo no solo son pertinentes y están en línea con lo dispuesto en el marco legal, sino que además son altamente deseables en el último curso de la formación académica de una buena parte del alumnado. Huelga decir que esta propuesta no pretende descuidar el carácter preparatorio para los exámenes de acceso a la universidad del curso en cuestión, pero que sí parte del supuesto de que dedicarle una sesión al debate y la reflexión sobre el tema de los refugiados a través de un texto literario puede contribuir a satisfacer las necesidades arriba comentadas y dispuestas en la LOMCE, que generalmente son pasadas por alto en el aula de Lengua castellana y Literatura.

\section{El teatro en el proceso de enseñanza-aprendizaje}

El uso del teatro en el aula debe responder a la naturaleza híbrida del teatro y, en este sentido, esta actividad propondrá una doble fase de aprovechamiento: en una primera fase el trabajo partirá del trabajo con el texto teatral y, posteriormente, se centrará en un proceso de dramatización que partirá de ese texto. Si bien es muy común trabajar con textos teatrales en el marco de la asignatura Lengua castellana y Literatura, lo cierto es que el trabajo performativo tiene, por lo general, un rol muy marginal en la etapa educativa del Bachillerato. En este epígrafe se abordarán, por tanto, las justificaciones teóricas de este uso del teatro en el aula, prestando especial atención a la segunda, por ser la más innovadora.

El trabajo con el texto seguirá una práctica muy asentada en las aulas: por un lado servirá para abordar en primera instancia el trabajo literario y, por otro, para fomentar la discusión. Esta práctica está en línea con la tendencia de enseñar, más que literatura, a apreciar la literatura y poner al alumnado "en disposición de poder 
apreciarla y valorarla" (Cerrillo, 20-21). Sin embargo, el acercamiento al texto estará guiado por la aproximación teórica de la "teatralidad implícita" (Santos Sánchez, 2009); es decir, se manejará la obra no únicamente como texto literario, sino también como manual para la puesta en escena, por lo que se incitará a las alumnas y los alumnos a que desplieguen en su imaginación, durante la lectura, la puesta en escena virtual, de manera que sean conscientes de la naturaleza escénica del teatro. Así, por un lado, se pretende incidir en la naturaleza híbrida del teatro como género que cuenta con un potencial que va más allá de la mera literatura, al tiempo que se incide también en una lectura de naturaleza más lúdica, por menos lineal y textual, que "desemboca en unos mejores resultados académicos y formadores" (Álvarez Ramos y Morán Rodríguez, 492). De este modo se pone de relieve otro de los motivos por los que se ha optado por un texto teatral: el teatro ofrece una lectura más lúdica y visual que otros géneros, como la narrativa, al tiempo que sienta de manera más directa las bases para una explotación posterior basada en la dramatización, cuyos beneficios se comentarán más abajo. Del mismo modo, en un curso como segundo de Bachillerato, en que los alumnos deben haber leído tres obras de la literatura española del siglo XX de cara a las pruebas de acceso a la universidad, se hace necesario garantizar que el teatro tenga su presencia entre esas lecturas. Esto es así porque, al menos en la mayoría de los casos, es de prever que los futuros lectores en que esos alumnos se han de convertir centrarán sus lecturas en géneros narrativos y solo de manera excepcional optarán por la lectura textos teatrales. Ante esta perspectiva se hace necesario garantizar que el alumnado termine esta etapa formativa habiéndose familiarizado con el texto teatral.

Más innovador es el uso de la dramatización en el aula que, pese a tener cierta tradición y gozar de presencia en las aulas de Primaria y ESO, no se ha integrado de manera satisfactoria en la etapa del Bachillerato. Esta realidad contrasta con la fuerte teorización que al respecto se ha formulado. En efecto, a medida que el proceso de enseñanza-aprendizaje comenzó en el siglo XX a despojarse de su carácter unidireccional y a otorgarle al alumno el rol de protagonista, haciendo del docente un mediador, el teatro y la educación comenzaron un fructífero diálogo que le confiere al primero un papel cada vez más relevante. No son pocos, en efecto, los teóricos que han reflexionado sobre la capacidad pedagógica del teatro:

Education can take place in an enormous variety of ways -not least through the medium of the arts. Any good theatre will of itself be educational -that is, when it initiates or extends a questioning process in its audience, when it makes us look afresh at the world, its institutions and conventions and at our own place in that world, when it expands our notion of who we are, of the feelings and thoughts of which we are capable, and of our connection with the lives of others (Jackson, 35)

Como resultado, y al margen de su presencia como asignatura dentro del área artística en Primaria o como optativa en la Educación Secundaria Obligatoria, el teatro ha ganado presencia y relevancia como una herramienta funcional y comunicativa que posibilita el proceso de enseñanza-aprendizaje en otras asignaturas, desde las Ciencias Sociales hasta la Educación Física. En efecto, el uso del teatro como dramatización es beneficioso no solo porque "los trabajos en grupo ayudan al alumnado a conocerse mejor y a tolerar las diferencias de actitud", sino también por el fuerte incremento motivacional que se deriva del "ejercicio de la experiencia directa o bien 
la actividad que los lleva [a los alumnos y las alumnas] a una vivencia o comprensión directa de los fenómenos" (Pérez Fernández, 173, 35-36). Integrar en el aula procesos de dramatización entraña, por tanto, múltiples beneficios que redundan en una mejora sustancial del aprendizaje al tiempo que sitúan al alumnado en el centro mismo de ese proceso. Ha de puntualizarse, sin embargo, que, como señala Özbek, el teatro en el aula "is not to be understood as a substitute method for traditional didactic strategies, but rather as a complementary teaching activity which may be used productively in order to achieve certain educational goals and objectives more efficiently" (46). De este modo, los métodos tradicionales han de convivir con un uso del teatro en el aula que, correctamente dosificado, puede redundar en beneficios a la hora de abordar algunos temas como, en nuestro caso, el de la xenofobia y los refugiados. Consideramos, además, que esta dosificación debe ser especialmente tenida en cuenta en el segundo curso de Bachillerato, sometido a las constricciones más arriba comentadas; pero, no obstante, defendemos que el uso de la dramatización es necesario ya que, por las ventajas que comporta, puede redundar en claros beneficios para el proceso de aprendizaje del alumnado.

Este uso educacional del teatro se inserta en la disciplina del Teatro Aplicado, que ha encontrado su fundamentación teórica en los últimos años tanto inicialmente en el ámbito anglosajón (Nicholson, 2005; Balme, 2008; Prentki y Preston, 2009; Shaughnessy, 2012) como posteriormente en España (Motos, 2013; Motos y Ferrandis 2015). Por Teatro Aplicado se entiende una disciplina de reciente aparición en el ámbito de los Estudios Teatrales y que se centra en el estudio y la práctica de cómo un amplio conjunto aspectos prácticos, desarrollados fuera de las instituciones teatrales convencionales y fundamentalmente basados en la participación del público, pueden servir para conseguir fines específicos ajenos al propio teatro y generalmente asociados a la transformación de la sociedad. Mientras que autores como Nicholson (2005) distinguen una amplia variedad de prácticas de Teatro Aplicado (Teatro en la Educación, Teatro Popular, Teatro del Oprimido, Teatro en la Educación Sanitaria, Teatro para el Desarrollo, Teatro Penitenciario, Teatro Museo, Teatro Reminiscencia y Teatro Comunitario), Motos y Ferrandis (2015) limitan la acción del Teatro Aplicado a cuatro grandes ámbitos: el teatro en la educación, el teatro social, la dramaterapia y el teatro en la empresa. Por su parte, Balme (2008) simplifica a tres usos: terapéuticos, educacionales o políticos. Sea como fuere, lo cierto es que el uso educativo del teatro aparece en todos los listados y se instituye en pilar básico del Teatro Aplicado.

Conviene tener claro que el uso del teatro en la educación se plantea, según la literatura especializada, en dos modalidades. Por un lado está el Teatro en la Educación (Theatre in Education, TIE): "a particular kind of theatre, practised by professional drama companies, or TIE teams, which work specifically in educational projects to be devised at schools" (Pérez Valverde, 8). Se trata de un uso profesional del teatro en la escuela que nace en los años 60 en Reino Unido y que, incluyendo tanto la propia práctica teatral como el trabajo previo y posterior en el aula, busca reconocer "the importance of the arts (and drama particularly) in the school curriculum, together with the increasing stress given to the functional role that the arts have to play in helping children to understand, and operate in, the world in which they live" (Jackson, 4). Por otro lado, la dramatización o el Drama en la Educación (Drama in Education, DIE) es el término que se aplica para el uso del teatro en el aula, como fin y como método, para trabajar cualquier aspecto del currículum. A diferencia de la primera opción, el DIE no requiere la presencia de actores profesionales, sino que 
es diseñado y guiado por el propio docente. De este modo, "drama is seen as an extension of play in the early stages" (Pérez Valverde, 13) y se muestra más viable en el aula, en tanto que no se necesitan para su práctica recursos ajenos al propio centro (la presencia de una compañía profesional de teatro) y, en consecuencia, puede usarse con más frecuencia para trabajar diferentes contenidos. Así, el DIE plantea "the creation of a dramatic environment where students learn the subject by playing roles and using other dramatic techniques while conducting a topic-related investigation" (Özbek, 50). Este enfoque es, por su mayor viabilidad en el entorno docente, el que sirve de marco teórico a la segunda parte de nuestra propuesta didáctica.

En su trabajo, Onieva (2001) señala cómo la dramatización o DIE puede aplicarse como recurso educativo a asignaturas como Historia, Matemáticas, Ciencias o Lengua y Literatura, entre otras. En el caso de la última, que compete a este trabajo, esta estrategia didáctica partirá, como se verá en la presentación de la propuesta, del texto para llegar, entre otros, a juegos del role play y debates donde los estudiantes adopten diversos papeles y defiendan sus opciones / opiniones. Esta aplicación resulta especialmente útil para los alumnos de segundo de Bachillerato, donde una práctica basada en el debate y la argumentación puede tener más rendimiento que la mera dramatización de una historia. Como señala el propio Onieva, los beneficios de la dramatización, en sus diversas modalidades, son iguales para todas las edades y "lo importante es adaptar los diferentes ejercicios dramáticos a los alumnos según su madurez" (162). En este sentido, el debate construido desde el DIE se muestra como un recurso adecuado no solo al nivel cognitivo de los alumnos en cuestión, sino también como un formato óptimo donde trabajar temas de derechos humanos y migraciones y, en consecuencia, forjar su capacidad crítica frente a problemas de la sociedad en que viven.

\section{El exilio republicano de 1939 en los cánones educativos}

Una de las responsabilidades de los docentes de Literatura, generalmente pasada por alto, es la de forjar el canon de los lectores del futuro. La elección de unas u otras lecturas a la hora de conformar los programas docentes tiene una enorme repercusión en las alumnas y los alumnos, que pueden desarrollar actitudes negativas o positivas hacia la Literatura y la lectura en función del canon forjado por el sistema educativo. Además, ese canon debe cumplir una serie de criterios éticos e históricos que garanticen una selección representativa y plural. Como ha señalado José Carlos Mainer, "todo canon es una lectura intencional del pasado, una simplificación más que a menudo, un ejercicio del poder sobre la literatura" (234). En el caso del canon que plantea la escuela, los criterios literarios o estéticos han sido tradicionalmente sustituidos por los pedagógicos (Cerrillo, 70), lo que redunda en una simplificación del mismo. Así, del mismo modo en que cada vez se afronta de una manera más crítica la inclusión de autoras en el canon que se lleva a las aulas, se hace también necesario responder a la reparación de la memoria literaria y poner remedio a las amputaciones a que el Franquismo sometió el canon de la literatura española del siglo XX, eliminando del mismo, entre otros, el exilio republicano de 1939. Es bien sabido que mientras en la España franquista la censura campaba a sus anchas, cercenando la creación cultural durante casi cuarenta años, los escritores republicanos que habían 
llevado las letras españolas al esplendor de la Edad de Plata siguieron desarrollando su labor en México o Buenos Aires, en lugar de en Madrid o Barcelona. La desconexión de los autores del que habría debido de ser su público natural, la falta de ediciones adecuadas y la deficitaria inclusión de esos autores en el canon educativo ya en democracia ha mantenido una parte fundamental de la literatura española alejada del público español.

La elección de San Juan de Max Aub como texto con que articular esta propuesta didáctica satisface varios criterios que, desde el punto de vista del canon, consideramos relevantes. Por un lado, cumple el que es uno de los deseos y las prioridades de los estudiosos de la literatura española contemporánea: la reparación y la inclusión del exilio en el canon. "En ese retorno definitivo y todavía pendiente de la obra literaria del exilio, lo prioritario no es tanto definir el lugar que ocupa en el contexto de la literatura española del siglo XX, como hacer posible el acceso de los lectores a esos textos vetados durante cuarenta años" (Rodríguez, sp). Esta labor de recuperación da respuesta al famoso "para quién escribimos nosotros" de Francisco Ayala (1948), al tiempo que pluraliza las lecturas que tradicionalmente se trabajan en segundo de Bachillerato. Consideramos que a la hora de escoger un texto del período 1939-1975² es más que legítimo optar por un texto del exilio, no ya solo como un gesto reparador sino también por la más que destacable calidad literaria de muchos de los textos de la España exterior. Por otro lado, la opción de San Juan pluraliza el catálogo de obras de teatro trabajadas en segundo de Bachillerato, cuya exigua nómina suele reducirse, en la mayoría de los casos, a La casa de Bernarda Alba, Luces de bohemia e Historia de una escalera. Estas obras, de fácil acceso y plenamente insertas en el canon, son con frecuencia puestas en escena, por lo que los alumnos pueden acceder a ellas sin dificultad, mientras que es más que probable que nunca conozcan el teatro de Max Aub de no incluirlo en un programa educativo. Por otra parte, escribir en las pruebas de acceso a la universidad sobre una obra menos tratada y, por tanto, más original puede ser un valor añadido que redunde en una mejor calificación.

Ricardo Domènech señala cómo el teatro del exilio republicano español de 1939 se centró en una serie de temas: el testimonio del presente histórico, la España perdida en 1939, el teatro mítico y el descubrimiento de América Latina a través del exilio (63-66). San Juan entra de manera categórica en la primera categoría al abordar sin ambages cómo un grupo de judíos de las más diversas procedencias se ven atrapados en el buque San Juan que, ante la negativa de todos los países a dejarle atracar, queda condenado a deambular sine die por el mar Mediterráneo. Como ha señalado Manuel Aznar, Max Aub "quiso testimoniar a través de su literatura toda esa experiencia personal en la convicción de que la función del dramaturgo en aquel tiempo histórico era la de 'reflejar la época', la de 'dar cuenta de la hora en crónicas más o menos verídicas" (233). Ese carácter al mismo tiempo testimonial y de denuncia de la obra es precisamente el que la dota de un enorme potencial para tratar en el aula, a través de su lectura, la diáspora judía y la xenofobia que son, junto con el Holocausto, temas en que incide, como hemos visto anteriormente, la LOMCE.

La obra, publicada en 1943 en México y en 1964 en España, se desarrolla íntegramente en el barco y durante un único día. La acción es fragmentaria, en tanto que

En la actualidad las pruebas de acceso a la universidad exigen de las alumnas y los alumnos tres lecturas sobre la literatura española del siglo XX: una del periodo que va hasta 1939, otra del periodo franquista (1939-1975) y otra del periodo post-1975. 
hay múltiples personajes que tienen diversas conversaciones en varios lugares del barco. Esta configuración incide en las características de cada uno de los personajes: hay judíos ricos y pobres, de izquierdas y de derechas, religiosos y seglares. Si bien cada personaje tiene una marcada identidad individual, esa diversidad no impide que todos den forma a un único personaje coral: el pueblo judío. Así consigue Max Aub representar la tragedia histórica de los judíos como un símbolo universal de todos los pueblos o colectivos oprimidos: desde los propios exiliados republicanos españoles hasta, como sugiere nuestra lectura contemporaneizadora, los refugiados y su triste peregrinaje a través, también, del Mediterráneo.

Como el resto de obras del teatro mayor de Aub, escrito íntegramente en el exilio, San Juan posee ese carácter políticamente comprometido que hace de él "un teatro 'ejemplar' que expresa el compromiso moral del dramaturgo con la reivindicación de la memoria histórica, un 'espejo' para el 'escarmiento' de sus lectores o espectadores" (Aznar, 238). Lo que pretende Aub es que sus personajes, pero también su público, "tras tomar conciencia de su trágica situación, pued[an] transformar la Historia y la realidad" (Aznar, 238). En efecto, la obra mueve a actuar: frente al fatalismo de las tragedias griegas, San Juan apunta cómo la realidad es susceptible de ser cambiada por la acción humana. No en vano los únicos que se salvan antes del naufragio son un grupo de jóvenes que deciden escapar del barco para ir a luchar, paradójicamente en España (la obra se desarrolla en los años de la Guerra Civil), contra el responsable de los males de los judíos: el fascismo.

Por otro lado, quienes intentan escapar del barco de manera individual no lo consiguen. La misma suerte corren quienes deciden buscar su salvación a través de la religión, que se hunden con el San Juan entre rezos. Aub lanza así un claro mensaje: los problemas de los judíos tienen una raíz y hay que atajar, de manera colectiva, esa raíz. La propuesta docente que planteamos para San Juan recoge esta lectura: detrás de la situación de los refugiados, colectivo perseguido y exiliado al igual que los judíos, hay una historia compleja sobre la que hay que reflexionar para, así, deshacer prejuicios contra ellos. A través de esta lectura contemporaneizadora no solo se trazan vínculos entre distintos colectivos marginados en distintos momentos de la historia, incidiendo en la repetición de problemas que siguen sin resolver, sino que también se le transmite al alumnado la impresión de que la literatura española no se centra exclusivamente en problemas domésticos, sino que cuenta también con una vertiente cosmopolita y atenta a problemas exógenos.

\section{Propuesta didáctica}

Nuestra propuesta didáctica, como se apuntó al principio del trabajo, pretende trabajar a través de un texto literario un contenido de actualidad desde una perspectiva crítica. Por tanto, y llevando a cabo el carácter integrador que propone la LOMCE, las competencias que vertebrarán la propuesta son tanto la social y cívica como la lingüística y la conciencia y expresión cultural. Del mismo modo, esta propuesta cubre varios de los objetivos generales que apunta la ley para la etapa del Bachillerato (BOE, 188):

a) Ejercer la ciudadanía democrática, desde una perspectiva global, y adquirir una conciencia cívica responsable, inspirada por los valores de la Constitución espa- 
ñola así como por los derechos humanos, que fomente la corresponsabilidad en la construcción de una sociedad justa y equitativa.

b) Consolidar una madurez personal y social que les permita actuar de forma responsable y autónoma y desarrollar su espíritu crítico. Prever y resolver pacíficamente los conflictos personales, familiares y sociales.

c) Fomentar la igualdad efectiva de derechos y oportunidades entre hombres y mujeres, analizar y valorar críticamente las desigualdades y discriminaciones existentes, y en particular la violencia contra la mujer e impulsar la igualdad real y la no discriminación de las personas por cualquier condición o circunstancia personal o social, con atención especial a las personas con discapacidad.

d) Afianzar los hábitos de lectura, estudio y disciplina, como condiciones necesarias para el eficaz aprovechamiento del aprendizaje, y como medio de desarrollo personal.

h) Conocer y valorar críticamente las realidades del mundo contemporáneo, sus antecedentes históricos y los principales factores de su evolución. Participar de forma solidaria en el desarrollo y mejora de su entorno social.

1) Desarrollar la sensibilidad artística y literaria, así como el criterio estético, como fuentes de formación y enriquecimiento cultural.

Del mismo modo, estos objetivos generales se concretan en otros dos de carácter más específico: el afianzamiento, por un lado, de la conciencia crítica sobre la diferencia cultural, la xenofobia y la tolerancia; y la toma de conciencia, por otro, de que la literatura es una herramienta con la que abordar problemáticas de la realidad.

Por otra parte, los contenidos generales de esta propuesta satisfacen los propios de la asignatura Lengua castellana y Literatura en el segundo curso de Bachillerato: el estudio cronológico de las obras más representativas de la literatura española del siglo XX hasta nuestros días; el análisis y la interpretación crítica de fragmentos u obras significativas de esa época; y la elaboración de presentaciones sobre temas, obras o autores de esa literatura. De manera más específica, y como se ha apuntado en las páginas precedentes, el tratamiento del teatro y su doble naturaleza textual y escénica, por un lado, y de la literatura del exilio republicano de 1939, por otro, son los contenidos específicos en torno a los que se articula esta propuesta didáctica. La actividad es rentable en tanto que no necesita recursos especiales y está diseñada para ser desarrollada en el aula habitual, desplazando las mesas para permitir un pequeño escenario en la parte delantera de la clase. El / la docente contará con tarjetas que incluyan los fragmentos que, como se verá a continuación, han de servir como punto de partida para cada una de las dramatizaciones y les serán entregados a los alumnos como objeto detonante para la actividad. Por su parte, la metodología será altamente participativa y se desarrollará tanto en pequeños grupos, para las dramatizaciones, como en gran grupo, para la parte de debate. Esta metodología está llamada a romper la dinámica del segundo curso de Bachillerato, caracterizada por la continua transmisión de contenidos, proponiendo una sesión de corte más lúdico que ponga al alumnado en el centro del proceso de enseñanza-aprendizaje y dispare, por las razones presentadas anteriormente, su motivación.

La secuenciación de esta propuesta responde a un modelo de tres fases: una breve contextualización inicial basada en el texto; la ejecución de una batería de actividades que, partiendo de algunos fragmentos del texto, proponen diversas dramatizaciones en los términos comentados más arriba; y una breve fase de cierre centrada 
en la reflexión en gran grupo. El esquema general de la sesión de aula es, por tanto, el siguiente:

\begin{tabular}{|c|c|}
\hline \multicolumn{2}{|c|}{ Secuenciación de la sesión } \\
\hline Fase previa & Lectura individual \\
\hline Contextualización & $\mathbf{1 0}$ minutos \\
\hline a) Presentación del autor por parte del / la docente & 5 minutos \\
\hline b) Discusión inicial en gran grupo sobre la obra & 5 minutos \\
\hline Ejecución & $\mathbf{3 0}$ minutos \\
\hline a) Tres dramatizaciones con el texto como punto de partida & 15 minutos \\
\hline b) Tres dramatizaciones de roles propuestos por el / la docente & 15 minutos \\
\hline Cierre & $\mathbf{1 0}$ minutos \\
\hline a) Debate sobre la necesidad de acoger refugiados sirios & 5 minutos \\
\hline b) Debate sobre la realidad de los republicanos exiliados & 5 minutos \\
\hline
\end{tabular}

\subsection{Fase previa y contextualización}

La actividad requiere de una fase previa de trabajo individual fuera del aula que permitirá que las alumnas y los alumnos hayan leído el texto de San Juan antes de la sesión única de cincuenta minutos en que se ha de desarrollar esta propuesta didáctica. Una vez en el aula comenzaremos con una primera fase de contextualización. Para incidir en el carácter abierto e integrador de la literatura española del que se hablaba en el epígrafe anterior, conviene comenzar la sesión dedicada a San Juan presentando la figura del propio autor. Max Aub no solo es uno de los autores más prolíficos y destacados del exilio republicano de 1939, sino que además encarna a la perfección ese carácter cosmopolita sugerido más arriba. Nacido en Francia en el seno de una familia de ascendencia judía y con sangre alemana, un Max Aub niño llega a España de manera fortuita $y$, tras aprender el español, hace de esta lengua su herramienta de expresión literaria. Su compromiso con la Segunda República le lleva a un largo exilio que, tras pasar por varias cárceles y campos de concentración franceses, depara con él en México, donde muere antes de que España dé por finalizado el franquismo. Tras esta breve presentación a manos del docente, de aproximadamente unos cinco minutos, podemos proceder durante otros cinco minutos a tratar en gran grupo el tema de la obra: ¿cuál es el mensaje de San Juan? ¿Qué opiniones tiene al respecto el alumnado? A continuación, tras estos diez minutos de actividad de calentamiento, abordaremos las actividades de dramatización, verdadero núcleo de nuestra propuesta, a la que dedicaremos media hora.

\subsection{Ejecución}

Como previamente se aclaró, la finalidad de nuestra actividad es fomentar la reflexión, tomando la obra de teatro como punto de partida, sobre los derechos de los 
refugiados y los migrantes en general. Para ello, la fase de ejecución, basada en el uso del DIE, constará de dos fases de unos quince minutos cada una. Primeramente se partirá de una selección de fragmentos del texto, proponiendo que los estudiantes asuman los papeles de algunos de los personajes de la obra con el fin de fomentar un debate sobre sus inquietudes, deseos y derechos. Posteriormente, en la segunda fase se organizará un debate dramatizado de índole más general, en que se asignen posturas contrapuestas sobre los derechos de los refugiados, no ciñéndose a los pasajeros del San Juan, sino a los refugiados sirios. Esta secuenciación pretende que el alumnado lleve a cabo un razonamiento inductivo que será culminado en la fase de cierre de la actividad.

En su trabajo sobre el uso educativo de la dramatización, Bowell y Heap (2001) plantean seis principios que deben estructurar el uso de este recurso por parte del docente en el aula: tema, contexto, roles, marco, signos y estrategias. Para la actividad que vamos a presentar en el aula, que ha de tomar una sesión de cincuenta minutos, hay que optar por una simplificación que la haga operativa. Por tanto, tendremos en cuenta de manera especial los cuatro primeros: el tema, que es aquello de lo que se va a tratar en la actividad; el contexto, que hace referencia a las circunstancias ficcionales en que se va a desarrollar la actividad; los roles, que son los papeles que van a desempeñar los estudiantes; y el marco, que es el desencadenante de la tensión y las contradicciones que guiarán la dramatización. En la primera fase de nuestra actividad, al partir de un texto teatral, estos elementos serán los mismos que en la propia obra. De esta manera pretendemos que las alumnas y los alumnos reproduzcan, de manera improvisada, algunas de las escenas de la obra en que se ponen de relieve una serie de oposiciones maniqueas que les harán reflexionar sobre el tema de las migraciones forzadas. El tema, por tanto, será el derecho de un grupo de judíos perseguidos a encontrar refugio, y el contexto será el de un barco de transporte que navega por el Mediterráneo. Los roles y el marco cambiarán en cada una de las dramatizaciones que se proponen para esta primera fase.

La primera fase de la ejecución incluye tres ejercicios de dramatización de cinco minutos cada uno. El primero de ellos girará en torno a la contraposición ideológica que se aprecia en ciertos pasajes de la obra. Los roles a desempeñar serán los de una serie de personajes que postulan la importancia de la libertad frente a los que optan por la intolerancia y, en consonancia, el marco será el odio religioso y étnico. En este sentido, la obra ofrece personajes con un fuerte maniqueísmo: mientras Lía y Chene impiden que su hija, judía, entable una relación sentimental con un miembro de la tripulación, que no lo es, Leva les reprocha su falta de tolerancia y pone de relieve cómo esa actitud de odio religioso es la misma que ha deparado con ellos en un barco al que no se le permite atracar en ningún lugar. Los fragmentos de partida para llevar a cabo esta dramatización, que ha de ser una discusión improvisada y argumentada, son los siguientes:

Lía. ¿Dónde está el Capitán? (A Chene.) ¡Vamos, muévete, muévete!

Chene. (Mareado.) No puedo. ¿No ves que no puedo?

Lía. ¿Y vas a dejar que tu hija se pierda para siempre?

Chene. Un primer oficial gana muy bien su vida. Es joven y pronto será capitán.

Lía. Nunca, ¿lo oyes?, nunca... Vamos. (Intenta hacerle subir la escalera; Chene no puede.) ¡Un hombre! ¿Tú eres un hombre? ¿No te da vergüenza?

(Aub, 171). 
Leva. La misma intolerancia que os echó de Colonia... Por el mismo motivo, por las mismas razones. ¿No ha oído nunca este grito?: ‘`No consentiremos que nuestra sangre se mezcle con otra impura!' ¿No le suena?

(Aub, 120).

Las alumnas y los alumnos encarnarán las visiones de estos personajes, dejando a un lado las suyas propias, para oponer las diversas actitudes respecto al diferente: desde la tolerancia hasta la xenofobia. Se trata de que la dramatización sirva de encuadre al debate posterior y muestre, además, cómo no existe homogeneidad dentro de un grupo de individuos que únicamente comparten una religión, pero que presentan valores opuestos en cuanto a la tolerancia, intereses ideológicos contrapuestos y muy diversas posiciones de clase social. En función del número de alumnos y alumnas con que cuente el aula se podrán insertar otros papeles en esta primera actividad. Un ejemplo, de entre tantos que se pueden tener en cuenta, sería el de Lázaro, judío que siente simpatía por Hitler; es decir, víctima que comparte los valores del verdugo, como manifiesta por sí mismo: “¿Por qué será Hitler antisemita? ¿Qué le hemos hecho? Porque si no fuera antisemita, yo no tendría nada contra él” (Aub, 121).

Una vez que hemos tratado la intolerancia religiosa y el clasismo, abordaremos una segunda dramatización en que el marco será la forma de salvación por la que optan los personajes y los roles serán los de varios de estos personajes que cuentan con opiniones contrapuestas al respecto: Bernheim, acaudalado judío que intenta chantajear al Capitán para que le deje abandonar el barco, y el propio Capitán, cuya rectitud le impide aceptar un chantaje y le lleva a considerar que todos los judíos merecen la misma consideración. El diálogo que dará pie a la dramatización es el siguiente:

Bernheim. [...] Pero..., ¿no le parece a usted un crimen que yo, con el dinero que poseo, tenga que ir por estas costas dando bandazos como todos estos pobrecitos que no tienen dónde caerse muertos? No, si yo no me quejo del trato a bordo: hacen ustedes lo que pueden... Pero, vamos a ver, mi Capitán: ¿no habría un medio de... desembarcarme? Un medio... natural, legal.

Capitán. Lo siento mucho, señor Bernheim.

Bernheim. No sé si usted me entiende, señor Capitán.

Capitán. Perfectamente.

Bernheim. Yo estaría dispuesto a dar lo que me pidiesen. (Pausa.) Cinco mil dólares, Capitán.

Capitán. Tengo trabajo, señor Bernheim.

Bernheim. (Lloroso.) Comprenda, señor Capitán. ¿Para qué me sirve aquí el dinero? Tengo cuatro hijos. ¡Usted tiene hijos! Siete mil dólares, Capitán.

Capitán. Para esto, se hubiese usted podido ahorrar los lloros sobre los demás.

Bernheim. ¿Acepta? Una vez en tierra...

Capitán. No, señor Bernheim. Si pudiera, lo haría por nada. Pero es imposible.

Además, han redoblado la vigilancia.

Bernheim. ¿Como si fuésemos apestados?

Capitán. Usted lo ha dicho, señor Bernheim. Y perdóneme, que tengo mucho que hacer.

(Aub, 123-124) 
El mensaje que Aub da en su obra es que el clasismo de Bernheim, que busca una salvación individual basada en su estatus y su nivel socio-económico, le impide salvarse. Por el contrario, únicamente aquellos que buscan una salvación colectiva, basada en la lucha contra la raíz del problema (el fascismo), consiguen escapar del barco antes de que se hunda al final de la obra. Este es el caso de Leva y sus compañeros:

Leva. [...] Camaradas: estamos perdiendo el tiempo miserablemente a bordo de este montón de hierro viejo cuando en otras partes del mundo hay una lucha efectiva. Hemos preparado nuestra marcha. No pensábamos que fuera tan pronto; pero, al saber que zarparíamos probablemente esta madrugada, hemos adelantado el plan. En tierra nos esperan.

Efraím. Pero, ¿cómo...?

Leva. Tú no te preocupes.

Ezequiel. ¿Y una vez en tierra?

Leva. Probablemente, a España.

Uno. Contad conmigo.

(Aub, 133)

La tercera dramatización sería un diálogo entre los jóvenes, cuyo compromiso político es férreo, y Bernheim, a quien solo mueve su propio interés personal por salvarse. En función de las necesidades que la actividad genere en el aula y para que todos los alumnos y las alumnas puedan participar en alguna de las dramatizaciones, otro integrante en este diálogo podría ser el rabino, que finalmente muere también, ya que pretende buscar la salvación a través de la religión, rezando en la última escena mientras el barco se hunde. La finalidad de este diálogo es incidir en la única viabilidad de la salvación a través del compromiso político e ideológico frente a otras opciones (las de Bernheim y el rabino), que en última instancia ha de llevar a las alumnas y los alumnos a reflexionar sobre la necesidad de encontrar soluciones colectivas con que poder atajar el problema de raíz y sin mirar para otro lado.

El segundo bloque de actividades dramatizadas de la fase de ejecución pondrá de relieve la lectura contemporaneizadora de la obra de Max Aub. En el propio texto de San Juan consta una nota del editor original del libro, Enrique Díaz-Canedo, que en 1943 ya apuntaba que el texto era una "tragedia de todos, en que cada cual, sea la que fuere su religión y raza, puede reconocerse en nuestros días" (Aub, 3). No en vano, el propio Aub incluye un fragmento que supone un contrapunto cómico a San Juan. En este fragmento un negro con acento caribeño entra en el barco, interesado por la naturaleza de sus pasajeros, y denuncia cómo se les está dando un trato similar al que recibe su colectivo, que suponemos de esclavos:

Negro. (a Sara.) ¿Usted des de a boldo?

Sara. Sí.

Negro. ¿De las que viajan?

Sara. Sí.

Negro. ¿Judía?

Sara. Sí.

Negro. (Muy desesperado.) ¡He peldido!

Sara. ¿Qué ha perdido? 
Negro. Una apuesta. Me dijeron que elan como todos. Yo no lo podía cleel. Polque, si son como todos, ¿pol qué no los habían de dejal desembalcal, no?

Sara. ¿Qué creía que éramos?

Negro. (Tras una duda, vergonzosamente.) Neglos...

(Aub, 127-128)

Este apunte cómico, que pretende introducir en la obra la supuesta equiparación del trato recibido por los judíos con el que han padecido otras comunidades víctimas del racismo y la xenofobia, ha de ser el punto de partida para la segunda fase de la actividad, meramente centrada en la situación de los refugiados sirios. Para ello, proponemos las siguientes pautas desde las que ejercitar la dramatización: el tema será el de la llegada de un buque con refugiados sirios a un puerto español y la negativa del gobierno a dejar que el pasaje desembarque; el contexto será la discusión, en un bar, entre varios personajes sobre los supuestos peligros que entraña la llegada de dichos refugiados. Podemos, para hilvanar esta fase de la actividad con la anterior, tomar del texto dos citas que actúen como punto de partida: las dos posiciones contrapuestas de Carlos, que genera odio en cadena sin preguntarse por las causas del mismo, y de Leva, que considera que debe haber una solución desde la que atajar el problema. Las citas en las que se sustentan estas actitudes son las siguientes:

Carlos. [en respuesta a “¿Por qué no dejas vivir a los demás?”] Porque los demás no me dejan vivir a mí (Aub, 113)

Leva: Siempre se puede hacer algo, sea donde sea (Aub, 112)

Se proponen tres dramatizaciones, también de cinco minutos de duración cada una, que aborden diferentes marcos. El primero de ellos será el del miedo al diferente y la intransigencia cultural. En esta dramatización un grupo de alumnas y alumnos adoptará posiciones más intransigentes (basadas en argumentos como "los sirios no son como nosotros", "no deben venir a España", "no es nuestro problema"), mientras que el otro deberá argumentar de manera proactiva dando ejemplos que lleven a los miembros del primer grupo a revisar sus afirmaciones ("los españoles han sido tradicionalmente emigrantes", "debemos ayudar a quien lo necesita", "los refugiados huyen precisamente del fanatismo religioso y muchos de ellos son cristianos"). Este debate parte de la primera actividad basada en el texto, donde los personajes planteaban posiciones ideológicas irreconciliables. El segundo de los ejercicios consistirá en un debate sobre la supuesta clase social de los refugiados y la capacidad económica de los mismos. Mientras que una parte del grupo defenderá el argumento de que los refugiados son en realidad exiliados económicos que vienen a España para robar los puestos de trabajo de la población local, la otra parte del grupo intentará mostrar cómo los refugiados son un colectivo diverso y plural dentro del cual hay, además, muchos profesionales de alta cualificación que vienen dispuestos a integrarse en el mercado laboral muy por debajo de su cualificación con tal de poder vivir en paz. Este ejercicio estará fundamentado en personajes como Bernheim, que pese a su fortuna comparten su destino con otros judíos pobres. Por último, la tercera dramatización propondrá dos grupos enfrentados sobre el modo de resolver la cuestión: mientras que unos harán una condena sin paliativos del Islam, los otros argumentarán que es una versión radical del Islam de la que huyen los refugiados y que la 
islamofobia únicamente contribuye a enquistar y agravar el problema. Nuevamente, este tercer ejercicio está enraizado en las oposiciones opuestas de los personajes de la obra dramatizados en el bloque de actividades anterior. Con esta segunda fase pretendemos, por tanto, iniciar en el alumnado un razonamiento inductivo que les lleve a trazar vínculos entre la obra y la realidad en que viven de manera crítica. Este razonamiento se verá culminado en la fase de cierre, donde el / la docente trazará un nuevo paralelismo llamado a generar, como se verá, más empatía en el alumnado.

\subsection{Cierre}

Tras esta media hora de ejecución de ejercicios dramatizados, en que debería haber participado el conjunto de la clase, la sesión se cerrará con una breve reflexión en gran grupo, en forma de debate y sin roles ni dramatización. Partiendo de los argumentos que se hayan desplegado en las dramatizaciones, se propondrá una discusión de diez minutos centrada en dos temas: primeramente se discutirá de manera libre sobre la necesidad de integrar a los refugiados sirios en España y, a continuación, se cerrará la sesión con una breve reflexión sobre el exilio republicano español de 1939, de manera que los alumnos tomen conciencia de que ese colectivo se vio obligado a sufrir una diáspora homologable a las de judíos y refugiados sirios. El / la docente fomentará un debate libre, ya sin reproducción de posiciones previamente asignadas, que ponga en común las reflexiones generadas por parte de las alumnas y los alumnos a lo largo de la sesión y les permita, a su vez, asumir un posicionamiento crítico sobre una situación del presente tras haberla ligado a otras situaciones homologables del pasado.

La ejecución estará basada en dos actividades de cinco minutos cada una. Primeramente se reflexionará sobre el rol que nuestra sociedad debe jugar en la acogida de los refugiados sirios y se cuestionará el odio al diferente, poniendo en tela de juicio la consolidación de la xenofobia y la islamofobia que han prendido mecha en algunos sectores de la sociedad. A continuación, y a modo de cierre, se lanzará la idea de que los republicanos españoles sufrieron una situación similar a la de los judíos del San Juan y a la de los refugiados sirios en la actualidad. El hecho de que Aub ideara su San Juan a bordo de un buque que le trasladaba a un campo de concentración es, en este sentido, un resorte óptimo que le ha de permitir al / a la docente vincular el exilio republicano con esos otros colectivos que han sufrido esa movilidad impuesta. De esta manera abriremos una reflexión en grupo sobre cómo, a través de la literatura, podemos trazar una línea entre el pasado y el presente. Al mismo tiempo, podremos plantearle a la clase cómo el prisma del presente (la situación de los refugiados) nos ha de permitir reflexionar sobre la situación de un grupo de españoles que, hace varias décadas, se vio forzado a un éxodo homologable al de los refugiados. Se espera, de este modo, que este cierre sirva para generar en el alumnado una mayor empatía.

\section{Conclusión}

El presente artículo pretende ser una aportación más a la didáctica de la literatura contemporánea y, en particular, del teatro, que en la actualidad se ha convertido en 
un foro de importante discusión teórica y práctica. Consideramos que la actividad propuesta satisface tres aspectos fundamentales que consideramos que redundan en un claro beneficio del proceso de enseñanza-aprendizaje: el trabajo transversal en valores, la incorporación del teatro como herramienta y la inclusión de la literatura del exilio. Primeramente, la actividad propuesta lleva al aula de Bachillerato una obra que trata un tema de especial interés para la LOMCE, como es la cuestión judía, al tiempo que permite una lectura en clave contemporánea que lo vincula con la situación de los refugiados y la necesidad de poner en tela de juicio la creciente islamofobia. De este modo no solo se introduce en el aula de manera transversal el tratamiento de los derechos humanos, sino que también se muestra a las alumnas y los alumnos que la literatura es una herramienta adecuada para tratar de entender la realidad en que se mueven. En última instancia, esta reflexión ha de estar encaminada al desarrollo del pensamiento crítico y de las actitudes cívicas en el alumnado.

Del mismo modo, el hecho de trabajar con un texto teatral facilita que la actividad esté articulada en torno a un ejercicio de dramatización primeramente basada en el texto y, a continuación, libre. Este tipo de trabajo no solo rompe la rutina del aula en un curso como segundo de Bachillerato, que en ocasiones peca de una excesiva rigidez basada en el desarrollo de contenidos, sino que además incrementa la motivación y genera un mayor compromiso con el tema tratado. Por último, la introducción de un texto del exilio en el programa de segundo de Bachillerato permite por un lado dilatar el corpus de textos tradicionalmente trabajados en este curso y, en consecuencia, enriquecer el canon literario, y, por otro, hace posible vincular a los exiliados republicanos de 1939 con otros grupo sometidos a exilios forzados, lo que a su vez puede permitirle al alumnado comprender cómo ciertos fenómenos se repiten de manera cíclica y cómo la obra literaria refleja esa recurrencia.

\section{Referencias bibliográficas}

Álvarez Ramos, E., y C. Morán Rodríguez (2016): “El cine y la literatura en el ámbito de la educación: principios metodológicos y sugerencias didácticas para el aula de Bachillerato", en Instructional Strategies in Teacher Training, Gómez, J., López, E. y Molina, L. (Eds.), San Juan, Puerto Rico, UMET, 492-500.

Aub, Max (2006): San Juan, Manuel Aznar Soler (ed.), Sevilla, Renacimiento.

Ayala, Francisco (1948): "Para quién escribimos nosotros", Guaraguao 5 (1997), 83-94.

Aznar Soler, Manuel (2003): Los laberintos del exilio. Diecisiete estudios sobre la obra literaria de Max Aub, Sevilla, Renacimiento.

Balme, C. (2008): The Cambridge Introduction to Theatre Studies, Cambridge, Cambridge University Press.

Boletín Oficial del Estado (2015): "Real Decreto 1105/2014, de 26 de diciembre, por el que se establece el currículo básico de la Educación Secundaria Obligatoria y del Bachillerato", Ministerio de Educación, Cultura y Deporte, Madrid (3 de enero de 2015), 169-546.

Bowell, Pamela, y Brian S. Heap (2001): Planning Process Drama, Londres, David Fulton. Cerrillo, Pedro C. (2010): Literatura Infantil y Juvenil y educación literaria. Hacia una nueva enseñanza de la literatura, Barcelona, Octaedro.

Doménech, Ricardo (2013): El teatro del exilio, Madrid, Cátedra. 
Jackson, Tony, ed. (1993): Learning through Theatre, Londres y Nueva York, Routledge.

Mainer, José Carlos (2000): Historia, literatura, sociedad (y una coda española), Madrid, Biblioteca Nueva.

Martín Vegas, Rosa Ana (2009): Manual de Didáctica de la Lengua y la Literatura, Madrid, Síntesis.

Motos, Tomás (2013): Otros escenarios para el teatro, Madrid, Ñaque.

Motos, Tomás y Domingo Ferrandis (2015): Teatro aplicado, Barcelona, Octaedro.

Nicholson, Helen (2005): Applied Drama. The Gift of Theatre, Nueva York, Palgrave MacMillan.

Onieva, J. (2011): La dramatización como recurso educativo: Estudio comparativo de una experiencia con estudiantes malagueños de un centro escolar concertado y adolescentes puertorriqueños en situación de marginalidad, Tesis doctoral, Universidad de Málaga. Disponible en: http://goo.gl/nuQt2R [consulta: 03-09- 2017].

Özbek, Gökçen (2014): “Drama in education: key conceptual features”, Journal of Contemporary Educational Studies 1, 46-61.

Pérez Fernández, J. (2011): Motivar en Secundaria. El teatro: una herramienta eficaz, Barcelona, Erasmus Ediciones.

Pérez Valverde, Cristina (2003): "Theatre in education (TIE) in the context of educational drama", Lenguaje y textos 20, 7-19.

Prentki, Tim, y Sheila Preston, eds. (2009): The Applied Theatre Reader, Londres y Nueva York, Routledge.

Rodríguez, Juan (2005): "El exilio literario en la periferia de la literatura española", en $L a$ Literatura y la Cultura del exilio republicano español de 1939: Actas del IV Coloquio Internacional: Hotel Las Lagunas, del 16 al 19 de julio de 2002, San Antonio de Baños, La Habana, Cuba, Alicante, Biblioteca Virtual Miguel de Cervantes, s.p.

Santos Sánchez, Diego (2009): "El análisis del texto y los Estudios Teatrales", en Motivos \& Estrategias, C. Alba y L. M. González (eds.), Leiria, Instituto Politécnico de Leiria / Universidad de Granada, 135-148.

Shaughnessy, Nicola (2012): Applying performance. Live art, socially engaged theatre and affective practice, Nueva York, Palgrave MacMillan.

Vila Carneiro, Zaida (en prensa, 2017): "Hacia una didáctica de la literatura áurea en el siglo XXI', Lenguaje y Textos. 